\title{
Mental health staff's knowledge and attitudes towards psychiatric patients' rights in Greece
}

\author{
Danilakoglou Christina', Filippiadou Magdalini', Papazisis Georgios ${ }^{2}$, Garyfallos Georgios ${ }^{1,}$ Bozikas Vasileios ${ }^{1}$

\section{$12^{\text {nd }}$ Department of Psychiatry, Psychiatric Hospital of Thessaloniki, School of Medicine,} \\ ${ }_{2}^{2}$ Department of Clinical Pharmacology, School of Medicine, \\ Aristotle University of Thessaloniki, Greece
}

Objectives: The purpose of the study was to investigate the mental health staff's knowledge and attitudes towards psychiatric patient's rights

Material and methods: A total number of 166 (52 men, 113 women) employees participated in the study, 42 of whom were psychiatrists and 114 nurses. The participants were staff members of different clinics of the Psychiatric Hospital of Thessaloniki. A questionnaire consisting of 35 questions was distributed and the response rate was 95\%. The statistical analysis was conducted using SPSS $(\mathrm{p}<0.05)$.

Results: The age of the participants ranged between 18-66 years. The majority $(67.5 \%, n=103)$ were under 50 years of age. Almost half of the sample $(47.6 \%, n=79)$ belonged to the age group of 36-50 years, followed by 50 years and over $(31.9 \%, \mathrm{n}=53)$. The majority $(59.6 \%, \mathrm{n}=99)$ of the respondents were married. $54.2 \%(n=90)$ of the participants had received higher education while $28.9 \%$ received secondary education. $30 \%$ of psychiatrists had a family member with psychiatric disease, whereas the corresponding percentage in nurses was $13 \%$. The attitudes of the professionals was significantly correlated with the educational level but not with the years of working experience. No correlation was found between the professional field (psychiatrists-nurses) and the attitude toward psychiatric patients. Both nurses and psychiatrists inform their patients regarding their rights, whereas a greater percentage of nurses than psychiatrists seem to be informed regarding psychiatric patients' rights. Finally, the attitude towards this group of patients depends on the mental health staff's knowledge.

Conclusions: The current study pointed out that better knowledge about psychiatric patients' rights leads to a more positive attitude towards this group of patients. Considering the fact that psychiatrists do not have a more positive attitude than nurses, it might be concluded that the existence of a multilevel educational program is becoming an immediate need, contributing in a great extend in the optimization of the provided health services.

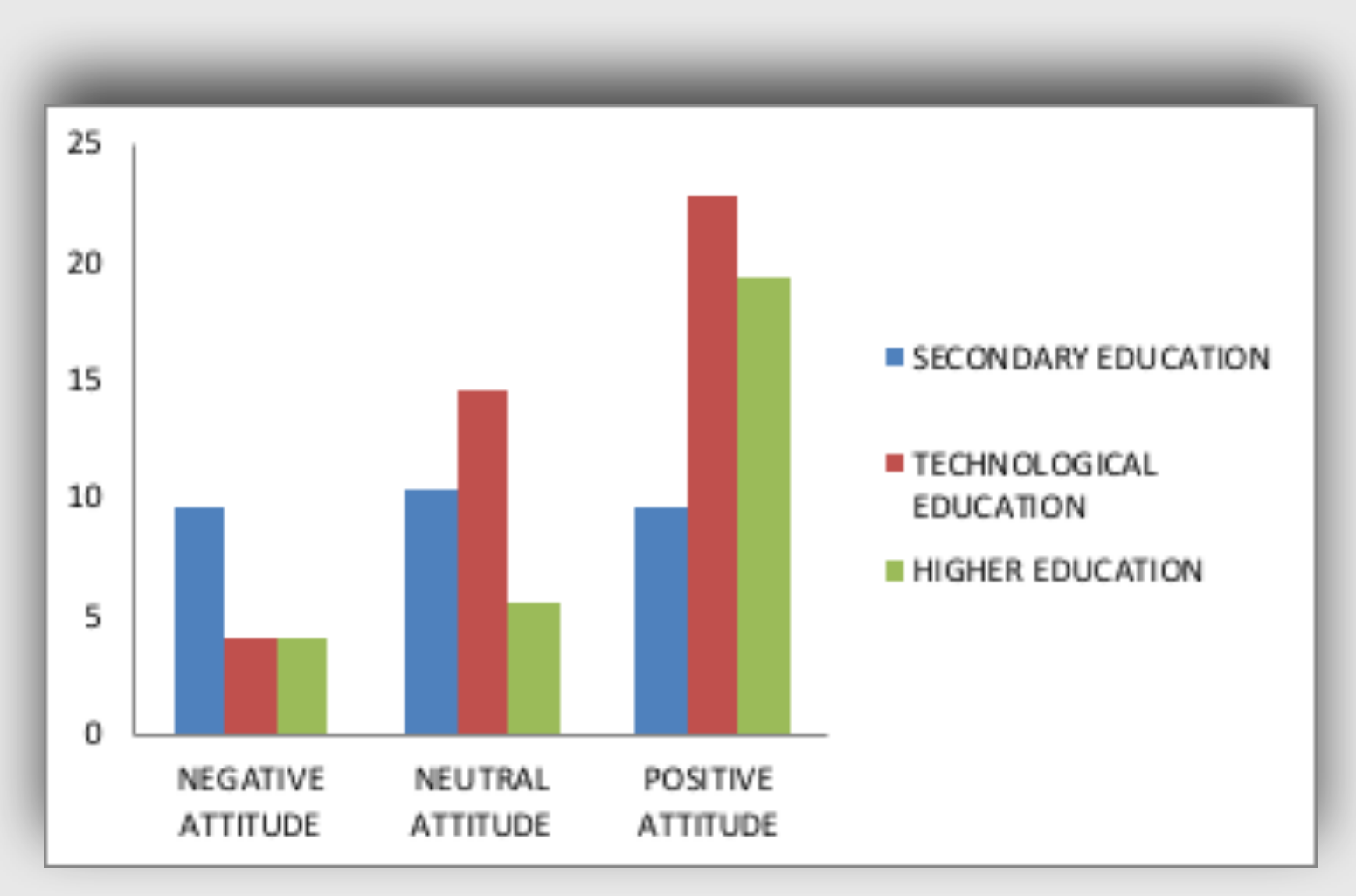

Figure 1: Correlation between attitude of mental health professionals towards mental health patients and their level of education

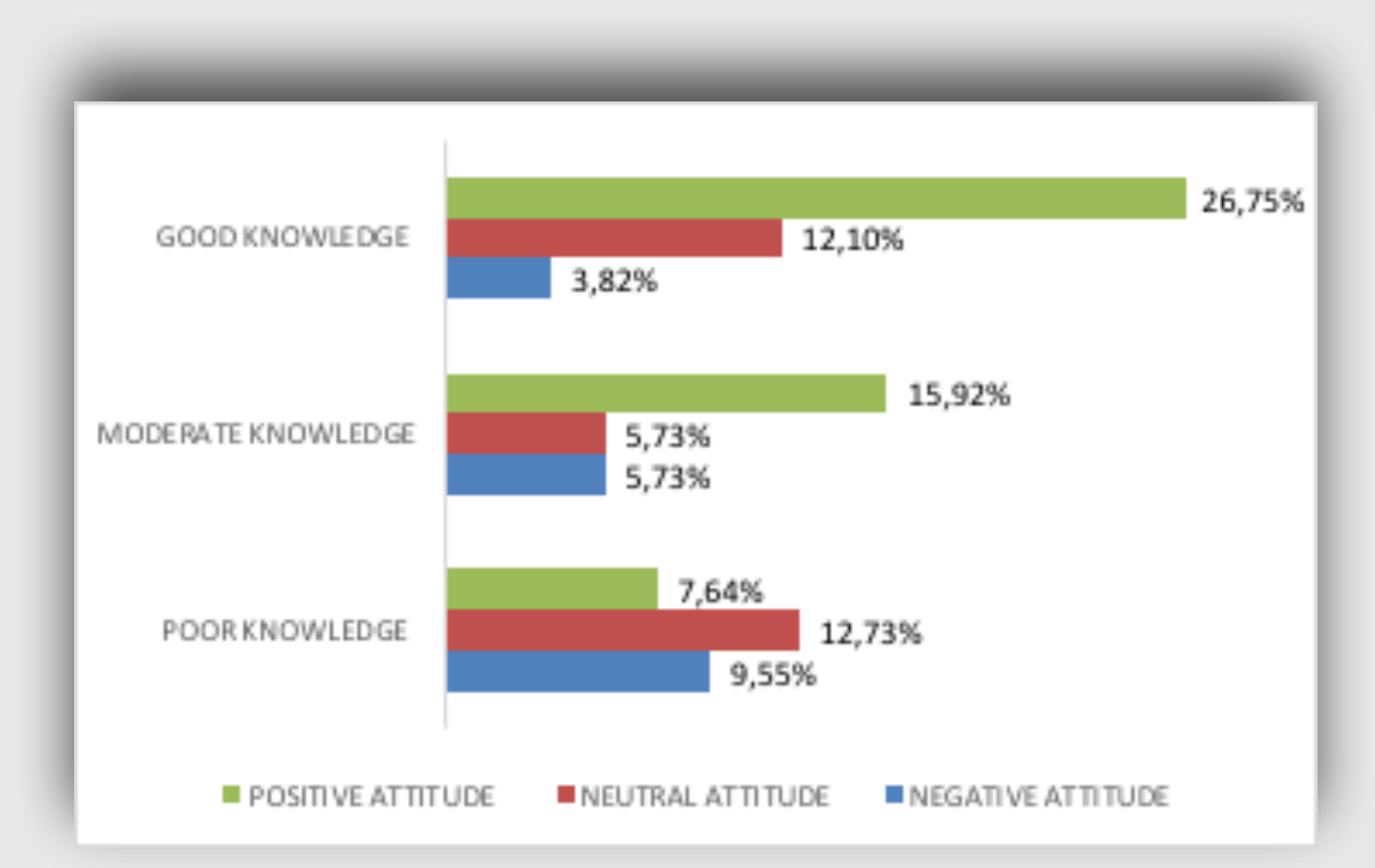

Figure 2: Correlation between knowledge of mental health professionals regarding the human rights of mental health patients and their attitude towards them Counselor: Research and Practice 2011,1(1):13-20,doi: 10.15241/als.1.1.13.

2.Hansson L, Jormfeldt $\mathrm{H}$, Svedberg P, Svensson B. Mental health professionals' attitudes towards people with mental illness: Do they differ from attitudes held by people with mental illness? International Journal of Social Psychiatry 2013, 59(1):48-54, doi: 10.1177/002076401142317621954319 